\title{
Factors associated with the initiation of breastfeeding within the first 48 hours of life in Tabuk, Saudi Arabia
}

\author{
Riyadh A. Alzaheb
}

\begin{abstract}
Background: The identification of the factors most closely associated with the initiation of breastfeeding is a vital first step in designing strategies to promote breastfeeding. The study therefore aimed to identify the factors that may be associated with the initiation of breastfeeding in the first $48 \mathrm{~h}$ after giving birth among mothers in Tabuk, Saudi Arabia.

Methods: This cross-sectional study was based on a sample of 671 mothers of infants aged up to 24 months at five primary healthcare centers between May and September 2015. A structured questionnaire was used to gather general sociodemographic data along with more detailed information on breastfeeding. A logistic regression analysis was then performed to establish the factors which were independently associated with the mothers' initiation of breastfeeding.

Results: Breastfeeding was initiated by $92.7 \%$ of mothers within the first $48 \mathrm{~h}$ after childbirth. Breastfeeding initiation within the first $48 \mathrm{~h}$ of childbirth was lower in women who gave birth by caesarean section (Adjusted Odds Ratio [AdjOR] 0.31, $95 \%$ Confidence Interval [CI] 0.17, 0.57), and had preterm (AdjOR 0.29, $95 \% \mathrm{Cl} 0.12,0.70$ ) or low birth weight infants (AdjOR 0.35, $95 \% \mathrm{Cl} 0.17,0.75$ ).

Conclusions: Each variable presents an important barrier to breastfeeding initiation. Suitable hospital policies and staff training are needed to support mothers in quickly initiating breastfeeding, and to discourage the use of infant formula in hospital. To encourage higher rates of exclusive breastfeeding in Saudi Arabia, additional support is required for mothers at a higher risk of failing to initiate breastfeeding in a timely manner.
\end{abstract}

Keywords: Breastfeeding initiation, New mothers, Preterm births, Low birth weight, Caesarean section, Public Health Policy

\section{Background}

The breastfeeding of infants has many benefits, as it provides them with the necessary nutrients for their optimal health and development as well as protecting them against infection [1-3]. Breastfeeding is also important for building a strong biological and emotional foundation for the infant's health and wellbeing, as well as that of their mother [4-7]. With these benefits in mind, the current recommendation from the World Health Organization (WHO) is that globally, for their

Correspondence: ralzaheb@ut.edu.sa

Department of Clinical Nutrition, Faculty of Applied Medical Sciences,

University of Tabuk, Tabuk City, Kingdom of Saudi Arabia first six months of life, infants should be exclusively breastfed [8].

The initiation of breastfeeding is vital to achieving the WHO's recommendation $[9,10]$, as it has been found to be associated with longer-term breastfeeding and lower infant mortality, particularly in developing countries [11, 12]. Several factors influence breastfeeding initiation: biomedical, sociodemographic, psychosocial, healthcare, community factors, and government policy. It should be noted that the relative importance of each of these areas differs across different regions and countries and also varies across population sub-groups [13-17]. In order that mothers are able to initiate

(c) 2016 The Author(s). Open Access This article is distributed under the terms of the Creative Commons Attribution 4.0 International License (http://creativecommons.org/licenses/by/4.0/), which permits unrestricted use, distribution, and reproduction in any medium, provided you give appropriate credit to the original author(s) and the source, provide a link to the Creative Commons license, and indicate if changes were made. The Creative Commons Public Domain Dedication waiver (http://creativecommons.org/publicdomain/zero/1.0/) applies to the data made available in this article, unless otherwise stated. 
breastfeeding in the first hours after giving birth, it is important that the factors that influence breastfeeding initiation are identified and understood $[18,19]$.

In the context of Saudi Arabia, a recent review by $\mathrm{Al}$ Juaid et al. (2014) has demonstrated that not enough information has been gathered by prior studies in relation to building an understanding of breastfeeding habits within Saudi Arabia that would enable the measurement of progress, or to plan and design programs to promote and encourage breastfeeding [20]. Unfortunately, no data have been gathered on breastfeeding or, specifically, on the potential factors influencing breastfeeding in Tabuk city (in the North-west region of Saudi Arabia). It is therefore difficult to identify which areas most require intervention among this community.

The aims of the current study are to estimate the occurrence of the initiation of breastfeeding within the first $48 \mathrm{~h}$ after childbirth among participating mothers of infants aged up to 24 months at the time of study in Tabuk, Saudi Arabia, and to identify the factors that may have an effect on the initiation of breastfeeding.

\section{Methods}

This cross-sectional study was carried out in Tabuk, Saudi Arabia, between May and September 2015. Tabuk is the largest city in north western Saudi Arabia and the capital of the Tabuk region, and had a population of 534,893 at the 2010 census. The sample size was calculated using the Epi-Info statistical program from the total of 12,760 live births registered in Tabuk in 2014, with a $50 \%$ prevalence assumed of breastfeeding initiation by mothers in the first $48 \mathrm{~h}$ after giving birth, a $95 \%$ confidence level, and a $5 \%$ confidence limit. The sample size calculated was 560 infants, which we approximated to 600 infants.

In the city of Tabuk, maternity and child care is provided through a network of 21 primary health care centers (PHCCs). PHCC services attract the majority of the population, who are generally members of the lower and medium socio-economic classes. Of the 21 PHCCs in Tabuk, five were chosen randomly for this research. A selection was made of one PHCC to represent each geographic region of Tabuk using random systematic sampling. More specifically, one PHCC located in each of the north, south, east, west and central areas of Tabuk was randomly selected after stratification by population density, socioeconomic status and geographical location was carried out. The five PHCCs selected for this study each received a letter from Tabuk's regional health administrator which included a fact sheet summarising the study's objectives, and inviting health professionals to help by facilitating the completion of the questionnaires.

A convenience sampling method was used to recruit mothers who attended the Well Baby Clinics within the chosen PHCCs with an infant aged $\leq 24$ completed months. These eligible mothers were approached in person and invited to an individual interview after they had received a proper orientation. If they agreed to be interviewed, they were supplied with an information sheet and asked to sign a consent form relating to their participation in the study.

\section{Data collection}

In total, 712 mothers were invited to take part in the study; of those, 671 eligible mothers completed the structured questionnaire while attending Well Baby Clinics within the five selected PHCCs, generating a response rate of $94.2 \%$. They were interviewed by trained, female, Arabic-speaking nurses at each PHCC. Data relating to two main areas were gathered in the study: sociodemographic information and detailed information on breastfeeding practices. The sociodemographic information gathered was as follows: the mother's age, their education, nationality, employment status, family income, number of children and the mode of delivery of their infant; also, the father's age, education, nationality and employment status; and the infant's age, sex, gestational age and birth weight. The detailed information gathered on breastfeeding practices related to the following areas: whether the infants had breastfed within the first $48 \mathrm{~h}$ after being born; if so, its duration in months, the frequency of breastfeeding across every 24-h period, the duration of exclusive breastfeeding and the time at which formula was introduced. In cases where the participating mother had more than one child who was younger than two years of age at the time of the research, the information collected from her was focused on her youngest child.

A pilot study involving 25 women was carried out with the purpose of testing the questionnaire which had been designed, so that changes could be made after their feedback had been collected and assessed. We found that the questionnaire took about $15 \mathrm{~min}$ to complete, and the pilot study participants were excluded from the final study sample.

\section{Definitions}

In this study, the definition of preterm delivery related to any live infant born at a gestation of $<37$ weeks. A low birth weight was taken to refer to any live infant born at a weight of $<2,500 \mathrm{~g}$ at birth. The outcome variable (initiation of breastfeeding) was set as having made at least one attempt to breastfeed in the first $48 \mathrm{~h}$ after giving birth.

\section{Data analysis}

All the data generated by the questionnaire were assigned appropriate codes, and an analysis was performed on them using the Statistical Package for the Social Sciences 
(SPSS) program, version 21.0. Univariate associations between various explanatory factors and the initiation of breastfeeding were identified and a multivariate logistic regression analysis was done in order to identify which of the factors had a direct influence on the initiation of breastfeeding, while simultaneously controlling for potential confounders. Odds ratios (OR) and their $95 \%$ confidence intervals $(\mathrm{CI})$ were calculated, $p \leq 0.05$ was chosen as the level of statistical significance. All the variables which emerged as having significant associations with breastfeeding initiation based on the univariate logistic regression analyses were then entered into the initial multivariate model. Variables which displayed no association with breastfeeding's initiation were excluded from the final logistic model, provided that they, and their removal from the model, would not have any meaningful effects on the associations between the other variables in the model. This assessment was based on an algorithm originally set out by Hosmer and Lemeshow [21], which has since been used by Tan [17].

\section{Results}

The participant characteristics of the sample $(n=671)$ are described in Table 1. Most of the mothers in the study sample were within the age group of 25-35 years old (60.8\%), and $48.6 \%$ of the mothers had received 12 or more years of schooling. The majority was of Saudi nationality $(89.9 \%)$, and the greater proportion was not in employment (78.5\%). With regard to monthly income, the largest group among the mothers (45.3\%) had a household income within the range of 5000-10000 Saudi Riyals per month and $63.5 \%$ of the mothers in this study were multiparous. The majority of births were vaginal deliveries $(74.8 \%)$ and $90 \%$ of the infants were born full term, and $11.8 \%$ of the mothers had gestational diabetes.

Table 2 contains the results of the univariate and multivariate logistic regression analysis used to identify the variables influencing the initiation of breastfeeding. The proportion of mothers who initiated the breastfeeding within the first $48 \mathrm{~h}$ after childbirth was $92.7 \%$. Among the sociodemographic variables in the univariate logistic regression analysis, the following factors were revealed to have been negatively associated with the initiation of breastfeeding: delivery by caesarean section (Odds Ratio [OR] 0.29, 95 \% CI 0.16, 0.52), mothers with infants who were born preterm (OR 0.23, $95 \%$ CI 0.10 , 0.54 ) and infants who were born with a low birth weight (OR 0.33, 95 \% CI 0.16, 0.68). The multivariate logistic regression analysis indicated that initiation of breastfeeding within $48 \mathrm{~h}$ was less likely in mothers who had given birth by caesarean section (Adjusted Odds Ratio [AdjOR] 0.31, $95 \%$ CI 0.17, 0.57), and who had preterm (AdjOR 0.29, $95 \%$ CI 0.12, 0.70) or low birth weight infants (AdjOR 0.35, $95 \%$ 0.17, 0.75).
Table 1 Participant characteristics $(n=671)$

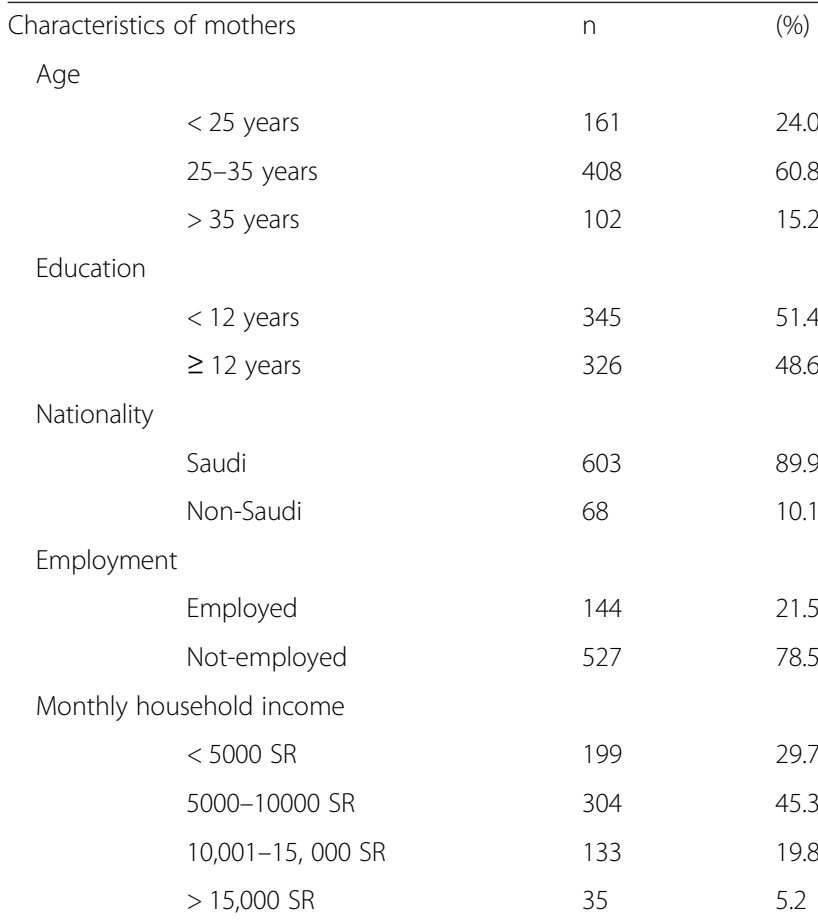

Number of children

One child

More than one

Mode of delivery

Vaginal

Gestation

$\begin{array}{lll}\text { Pre term infant } & 35 & 5.2 \\ \text { Full term infant } & 636 & 94.8\end{array}$

Gestational diabetes

$$
\text { Yes }
$$

Do not know

Characteristics of fathers

Age

$\begin{array}{lll}<\mathrm{V} 25 \text { years } & 7 & 1.0 \\ 25-35 \text { years } & 384 & 57.2 \\ >35 \text { years } & 280 & 41.7\end{array}$

Education

$\begin{array}{lll}<12 \text { years } & 403 & 60.1 \\ \geq 12 \text { years } & 268 & 39.9\end{array}$

Nationality

Saudi

Employment 
Table 1 Participant characteristics $(n=671)$ (Continued)

\begin{tabular}{|c|c|c|c|}
\hline & Not-employed & 61 & 9.1 \\
\hline \multicolumn{4}{|c|}{ Characteristics of Infants } \\
\hline \multicolumn{4}{|c|}{ Age } \\
\hline & $0-3$ months & 39 & 5.8 \\
\hline & 4-6 months & 129 & 19.2 \\
\hline & 7-9 months & 67 & 10.0 \\
\hline & 10-12 months & 201 & 30.0 \\
\hline & 13-15 months & 38 & 5.7 \\
\hline & 16-18 months & 85 & 12.7 \\
\hline & 19-21 month & 18 & 2.7 \\
\hline & 22-24 months & 94 & 14.0 \\
\hline \multicolumn{4}{|c|}{ Gender } \\
\hline & Male & 357 & 53.2 \\
\hline & Female & 314 & 46.8 \\
\hline \multicolumn{4}{|c|}{ Birth weight } \\
\hline & Low birth weight & 65 & 9.7 \\
\hline & Normal birth weight & 606 & 90.3 \\
\hline
\end{tabular}

Yrs years, SR Saudi Riyal, mos months

\section{Discussion}

Of the 671 mothers surveyed in this study, $92.7 \%$ had initiated breastfeeding within the first $48 \mathrm{~h}$ after childbirth, a figure which is consistent with the findings of a recent review of breastfeeding in Saudi Arabia [20]. The authors of that review reported high initiation rates of between 90.1 and $98.9 \%$ in most of the identified studies.

Breastfeeding initiation rates vary across the different countries in the Middle Eastern region. Ninety-five per cent of mothers in the Emirate of Abu Dhabi reported that they initiated breastfeeding after giving birth [22]. This finding is close to that of a research study in Kuwait [23] which reported that the rate of breastfeeding initiation at hospital discharge was $92.5 \%$, but the figure for Qatar [24] was much lower as only $57 \%$ of mothers reported an early initiation of breastfeeding. A more recent study in Iran reported that $100 \%$ of mothers had started breastfeeding in hospital [25]. Other studies have shown that in Jordan [26], 74 \% of new mothers initiated breastfeeding within two hours of giving birth, but only $18.3 \%$ of new mothers in Lebanon started to breastfeed in the first 30 min after giving birth [27].

The present research has not found any significant association between the initiation of breastfeeding in the first $48 \mathrm{~h}$ after delivery and the demographic attributes of the mother's age, education, nationality, employment status, family income, number of children, or infant's gender. By way of comparison, several studies in the Middle East and in other countries around the world have previously examined the possible associations between the initiation of breastfeeding and some or all of these characteristics, but significant associations have not always been found. A recent review of 15 studies examining breastfeeding in Saudi Arabia summarised that, in terms of the effects of maternal age on breastfeeding, only eight of the studies found a significant association as the breastfeeding initiation rate was higher and breastfeeding was, on average, done for longer by older mothers [20]. Elsewhere, no significant relationship was found between the age of the mother and their breastfeeding practice by a study in Kuwait [23] or by a study in the United Arab Emirates [28]. In another systematic review of 18 research studies from Asia, Africa and South America each of which aimed to identify independent risk factors preventing breastfeeding within the first hour of life, neither the age of the mother nor other factors such as family income or schooling were found to be independent determinants by most of the studies [11].

This study has identified three factors as having statistically significant associations with breastfeeding initiation. The first of these factors, delivery by caesarean section, was inversely associated with breastfeeding initiation. This is consistent with previous studies in Saudi Arabia [13, 29, 30], which identified caesarean section as a risk factor for breastfeeding initiation. For instance, Albokhary and James examined a sample from the western region of Saudi Arabia and found that mothers who had given birth vaginally had a greater likelihood of starting breastfeeding within $24 \mathrm{~h}$, while caesarean section babies were more likely to be formula fed [29]. This negative association of caesarean delivery with breastfeeding initiation has also been reported in a study of Kuwaiti mothers [23] and by a systematic review of worldwide studies which found that 11 out of 14 studies supported the association [11]. Two possibilities have been proposed for this negative association: that the effects of anesthesia delay lactation, and/or post-surgical pain [29, 30].

The present study also identified two other factors which had significant associations with the initiation of breastfeeding. These were gestational age and the infant's birth weight. More specifically, breastfeeding is less likely to be initiated by mothers with preterm infants and those with infants born at a low birth weight. To the best of the author's knowledge, only one study previously published in Saudi Arabia has examined gestational age and infant birth weight as possible influencing factors, and found them to be potentially detrimental to breastfeeding initiation [31]. A systematic review [11] was carried out to identify the risk factors likely to lead to breastfeeding not being started within an hour after an infant's birth. In total, 18 articles met the inclusion criteria, and they were carried out in Asia (9), Africa (5), and South America (4). Only three of them examined the possible association of premature birth with non-breastfeeding, and of those, 
Table 2 Factors associated with the initiation of breastfeeding within the first $48 \mathrm{~h}$ of the infant's life $(n=671)$

\begin{tabular}{|c|c|c|c|c|c|c|}
\hline \multirow[t]{2}{*}{ Variables } & \multicolumn{2}{|c|}{ Initiation of breastfeeding } & \multicolumn{2}{|c|}{ Univariate } & \multicolumn{2}{|c|}{ Multivariate } \\
\hline & $\begin{array}{l}\text { Yes } \\
n=622(92.7 \%)\end{array}$ & $\begin{array}{l}\text { No } \\
n=49(7.3 \%)\end{array}$ & $\overline{\mathrm{OR}}$ & $95 \% \mathrm{Cl}$ & $\overline{A d j O R}$ & $95 \% \mathrm{Cl}$ \\
\hline \multicolumn{7}{|l|}{ Mother's age } \\
\hline$<25$ years & $155(96.3)$ & $6(3.7)$ & 1.05 & $0.29,3.83$ & & \\
\hline $25-35$ years & $369(90.4)$ & $38(9.3)$ & 0.39 & $0.14,1.11$ & & \\
\hline$>35$ years & $98(96.1)$ & $4(3.9)$ & 1 & Ref & & \\
\hline \multicolumn{7}{|l|}{ Mother's education } \\
\hline$<12$ years & $320(92.8)$ & $24(7.0)$ & 1.02 & $0.57,1.82$ & & \\
\hline$\geq 12$ years & $302(92.6)$ & $24(7.4)$ & 1 & Ref & & \\
\hline \multicolumn{7}{|l|}{ Mother's nationality } \\
\hline Saudi & $557(92.4)$ & $45(7.5)$ & 0.56 & $0.17,1.85$ & & \\
\hline Non-Saudi & $65(95.6)$ & $3(4.4)$ & 1 & Ref & & \\
\hline \multicolumn{7}{|l|}{ Mother's dmployment } \\
\hline Employed & $128(88.9)$ & $15(10.4)$ & 0.53 & $0.29,1.00$ & & \\
\hline Not-employed & $494(93.7)$ & $33(6.3)$ & 1 & Ref & & \\
\hline \multicolumn{7}{|c|}{ Monthly household income } \\
\hline$<5000 S R$ & $186(93.5)$ & $13(6.5)$ & 0.87 & $0.19,4.02$ & & \\
\hline $5000-10000$ SR & $275(90.5)$ & $28(9.2)$ & 0.58 & $0.13,2.52$ & & \\
\hline $10,001-15,000 S R$ & $128(96.2)$ & $5(3.8)$ & 1.55 & $0.29,8.36$ & & \\
\hline$>15,000 \mathrm{SR}$ & $33(94.3)$ & $2(5.7)$ & 1 & Ref & & \\
\hline \multicolumn{7}{|l|}{ Number of children } \\
\hline One child & $226(92.2)$ & $18(7.3)$ & 0.90 & $0.50,1.64$ & & \\
\hline More than one & $396(93.0)$ & $30(7.0)$ & 1 & Ref & & \\
\hline \multicolumn{7}{|l|}{ Mode of delivery } \\
\hline Caesarean section & $144(85.2)$ & $25(14.8)$ & 0.29 & $0.16,0.52$ & 0.31 & $0.17,0.57$ \\
\hline Vaginal & $478(95.2)$ & $23(4.6)$ & 1 & Ref & 1 & Ref \\
\hline \multicolumn{7}{|l|}{ Gestation } \\
\hline Preterm infant & $27(77.1)$ & $8(22.9)$ & 0.23 & $0.10,0.54$ & 0.29 & $0.12,0.70$ \\
\hline Full term infant & 595 (93.6) & $40(6.3)$ & 1 & Ref & 1 & Ref \\
\hline \multicolumn{7}{|l|}{ Infant's gender } \\
\hline Male & $333(93.3)$ & $24(6.7)$ & 1.20 & $0.67,2.15$ & & \\
\hline Female & $289(92.0)$ & $24(7.6)$ & 1 & Ref & & \\
\hline \multicolumn{7}{|l|}{ Infant birth weight } \\
\hline Low birth weight & $54(83.1)$ & $11(16.9)$ & 0.33 & $0.16,0.68$ & 0.35 & $0.17,0.75$ \\
\hline Normal birth weight & $568(93.7)$ & $37(6.1)$ & 1 & Ref & 1 & Ref \\
\hline
\end{tabular}

CI Confidence Interval, OR Odds Ratio, AdjOR Adjusted Odds Ratio, Ref Reference

two studies found that infants born prematurely had significantly less chance of rapidly initiated breastfeeding than full term infants. The remaining study found no association between prematurity and breastfeeding. Further, only five of the 18 studies investigated the possible connection between infants' birth weights and breastfeeding initiation. Of those five, one identified an association, while the other four did not.
As is the case with all such studies, this study contains some potential limitations. This study's first, and most important, limitation is the cross-sectional design of the research. This design does not allow causal inferences to be drawn from any of the associations which are found to exist between the identified determinant factors and breastfeeding initiation. A cross-sectional design also has the inherent limitation of recall bias, especially with 
regard to mothers who have older infants, as their recollections may be less accurate. The study has a second limitation in that it only used mothers who were attending governmental PHCCs, who were interested in breastfeeding and, therefore, in participating. It also excluded mothers who were receiving similar care at other health facilities, including those in the private sector. Overall, the nature of the sample might be said to restrict the generalizability of the study.

\section{Conclusions}

The key finding of this study is that the initiation of breastfeeding within $48 \mathrm{~h}$ was less likely to be reported by mothers who had given birth by caesarean section, and had preterm or low birth weight infants. These variables each present important barriers to breastfeeding initiation, which hospitals could assist in overcoming. Suitable hospital policies and staff training must therefore be implemented in order to support mothers in initiating breastfeeding soon after giving birth, and to discourage them from giving their babies infant formula unnecessarily in hospital. A particular focus should be placed on providing additional support to mothers identified as being at a higher risk of failing to initiate breastfeeding, so that higher rates of exclusive breastfeeding can be encouraged and achieved in Saudi Arabia.

\section{Acknowledgments}

The author would like to acknowledge financial support for this work from the Deanship of Scientific Research (DSR) at the University of Tabuk, Saudi Arabia (grant number: S-1436-0289).

\section{Competing interests}

The author declares that he has no competing interests.

\section{Ethics approval and consent to participate}

Ethical approval for this study was obtained from the Committee of Research Ethics at the University of Tabuk (HAP-07-TU-001).

Received: 25 February 2016 Accepted: 4 July 2016

Published online: 21 July 2016

\section{References}

1. Agostoni C, Scaglioni S, Ghisleni D, Verduci E, Giovannini M, Riva E. How much protein is safe? Int J Obes (Lond). 2005;29 Suppl 2:S8-S13.

2. Koletzko B, Shamir R, Ashwell M. Quality and safety aspects of infant nutrition. Ann Nutr Metab. 2012:60(3):179-84.

3. Robinson S, Fall C. Infant nutrition and later health: a review of current evidence. Nutrients. 2012:4(8):859-74

4. Hornell A, Lagstrom H, Lande B, Thorsdottir I. Breastfeeding, introduction of other foods and effects on health: a systematic literature review for the 5th Nordic Nutrition Recommendations. Food Nutr. Res. 2013; 57. http://doi.org/ 10.3402/fnr.v57i0.20823.

5. Kramer MS, Kakuma R. Optimal duration of exclusive breastfeeding. Cochrane Database Syst Rev. 2012:8:CD003517.

6. Luan NN, Wu QJ, Gong TT, Vogtmann E, Wang YL, Lin B. Breastfeeding and ovarian cancer risk: a meta-analysis of epidemiologic studies. Am J Clin Nutr. 2013;98(4):1020-31.

7. Schack-Nielsen L, Michaelsen KF. Advances in our understanding of the biology of human milk and its effects on the offspring. J Nutr. 2007;137(2):503S-10S.

8. World Health Organization, UNICEF. Global Strategy for Infant and Young Child Feeding. Geneva: WHO; 2003.
9. DiGirolamo AM, Grummer-Strawn LM, Fein SB. Effect of maternity-care practices on breastfeeding. Pediatrics. 2008;122 Suppl 2:\$43-9.

10. Moore ER, Anderson GC, Bergman N, Dowswell T. Early skin-to-skin contact for mothers and their healthy newborn infants. Cochrane Database Syst Rev. 2012;5:CD003519.

11. Esteves TM, Daumas RP, Oliveira MI, Andrade CA, Leite IC. Factors associated to breastfeeding in the first hour of life: systematic review. Rev Saude Publica. 2014;48(4):697-708.

12. Lawn JE, Cousens S, Zupan J. 4 million neonatal deaths: when? Where? Why? Lancet. 2005;365(9462):891-900.

13. Amin T, Hablas H, Al Qader AA. Determinants of initiation and exclusivity of breastfeeding in Al Hassa. Saudi Arabia Breastfeed Med. 2011;6(2):59-68.

14. Leahy-Warren P, Mulcahy H, Phelan A, Corcoran P. Factors influencing initiation and duration of breast feeding in Ireland. Midwifery. 2014:30(3):345-52.

15. Li L, Zhang M, Scott JA, Binns CW. Factors associated with the initiation and duration of breastfeeding by Chinese mothers in Perth, Western Australia. J Hum Lact. 2004;20(2):188-95.

16. Merewood A, Patel B, Newton KN, MacAuley LP, Chamberlain LB, Francisco $P$, \& Mehta SD. Breastfeeding duration rates and factors affecting continued breastfeeding among infants born at an inner-city US Baby-Friendly hospital. J Hum Lact. 2007:23(2):157-64.

17. Tan KL. Factors associated with exclusive breastfeeding among infants under six months of age in peninsular malaysia. Int Breastfeed J. 2011;6:2.

18. Alikasifoglu M, Erginoz E, Gur ET, Baltas Z, Beker B, Arvas A. Factors influencing the duration of exclusive breastfeeding in a group of Turkish women. J Hum Lact. 2001;17(3):220-6.

19. Patel A, Banerjee A, Kaletwad A. Factors associated with prelacteal feeding and timely initiation of breastfeeding in hospital-delivered infants in India. J Hum Lact. 2013;29(4):572-8.

20. Al Juaid DA, Binns CW, Giglia RC. Breastfeeding in Saudi Arabia: a review. Int Breastfeed J. 2014;9:1.

21. Hosmer DW, Lemeshow S. Applied Logistic Regression. 2nd ed. Wiley and Sons: New York; 2000.

22. Gardner H, Green K, Gardner A. Infant feeding practices of Emirati women in the rapidly developing City of Abu Dhabi, United Arab Emirates. Int J Environ Res Public Health. 2015:12(9):10923-40.

23. Dashti M, Scott J, Edwards CA, Al-Sughayer M. Determinants of breastfeeding initiation among mothers in Kuwait. Int Breastfeed J. 2010:5.7.

24. Al-Kohji S, Said HA, Selim NA. Breastfeeding practice and determinants among Arab mothers in Qatar. Saudi Med J. 2012;33(4):436-43.

25. Mortazavi F, Mousavi SA, Chaman R, Wambach KA, Mortazavi SS, Khosravi A. Breastfeeding practices during the first month postpartum and associated factors: impact on breastfeeding survival. Iran Red Crescent Med J. 2015;17(4):e27814

26. Oweis A, Tayem A, Froelicher ES. Breastfeeding practices among Jordanian women. Int J Nurs Pract. 2009;15(1):32-40.

27. Batal M, Boulghourjian C, Abdallah A, Afifi R. Breast-feeding and feeding practices of infants in a developing country: a national survey in Lebanon. Public Health Nutr. 2006:9(3):313-9.

28. Osman NA, el-Sabban FF. Infant-feeding practices in Al-Ain, United Arab Emirates. East Mediterr Health J. 1999:5(1):103-10.

29. Albokhary AA, James JP. Does cesarean section have an impact on the successful initiation of breastfeeding in Saudi Arabia? Saudi Med J. 2014; 35(11):1400-3

30. Dorgham L, Hafez S, Kamhawy H, Hassan W. Assessment of initiation of breastfeeding, prevalence of exclusive breast feeding and their predictors in Taif, KSA. Life Sci J. 2014;11:1

31. El-Gilany $\mathrm{AH}$, Sarraf $\mathrm{B}$, Al-Wehady A. Factors associated with timely initiation of breastfeeding in Al-Hassa province, Saudi Arabia. East Mediterr Health J. 2012;18(3):250-4. 